\title{
Fetichismo e narcisismo: a base do capitalismo?
}

Resumo: 0 presente artigo analisa os conceitos de fetichismo e narcisismo, baseando-se nas análises de Marx do fetichismo da mercadoria e do narcisismo em Freud. Uma leitura mais ampla reflete sobre o fetichismo como determinante das próprias formas do pensamento e do agir, enquanto o narcisismo, ultrapassando o simples comportamento individualista, danifica também a própria vida coletiva. Trata-se, portanto, de compreender se esses dois conceitos permitem um uso mais profundo que chegue ao coração da sociedade contemporânea - um uso que deveria decorrer de uma leitura inovadora da constituição fetichismo-narcisismo, sem, contudo, tomá-la sempre ao pé da letra.

Palavras-chave: Fetichismo, Narcisismo, Crítica do valor, Trabalho, Marxismo.

\section{FETISHISM AND NARCISSISM: THE BASIS OF CAPITALISM?}

\begin{abstract}
The article offers an analysis of the concepts of fetishism and narcissism, based on Marx's analysis of commodity fetishism and narcissism in Freud. A wider reading reflects on fetishism as determinant of the very forms of thinking and acting, while narcissism, going beyond simple individualistic behaviour, also damages the collective life itself. It is a question therefore of understanding whether these two concepts allow a deeper use that reaches the heart of contemporary society - a use that should derive from an innovative reading of the fetish-narcissistic constitution, without, however, always taking it strictly.
\end{abstract}

Keywords: Fetishism, Narcissism, Critique of value, Work, Marxism.

1 Academia de Belas-Artes de Sassari. 
"Fetichismo" e "narcisismo" são dois termos que, frequentemente, ouvimos nos discursos cotidianos, sobretudo nos últimos tempos. À primeira vista, o significado deles parece bem claro. 0 narcisismo é a atitude daquele ou daquela que se olha constantemente no espelho e enaltece seu próprio aspecto exterior e, em geral, além disso, indica uma pessoa egoísta, por demais convencida de suas qualidades, que quer fazer o mundo, e sobretudo a vida dos outros, girar em volta de si. Tornase, então, um perigo ter uma pessoa narcisista no ambiente de trabalho, principalmente quando se trata de um chefe, e é uma desgraça tê-la como parceira em uma relação. Segundo uma afırmação corrente, as redes sociais têm aumentado fortemente a tendência narcisista na sociedade.

O fetichismo, ao contrário, indica um amor considerado excessivo por alguma coisa (um objeto, um comportamento, uma pessoa). Assim, por exemplo, podemos encontrar um fetichista da música de Rossini ou, em relação ao fetichismo sexual, do qual fala Sigmund Freud, um homem que se excita vendo sapatos de salto alto ou de couro. Com frequência, são feitas referências ao "fetichismo da mercadoria", introduzido por Marx no debate, e é referido, em seguida, normalmente para condená-lo, àqueles que adoram um automóvel grande ou determinada marca de roupas, em cujo consumo, suspeita-se, deve esconder-se a pobreza de suas vidas.

Esses usos das palavras "fetichismo" e "narcisismo" não são falsos: eles abarcam fenômenos bem reais e com os quais nos deparamos todos os dias. $\mathrm{E}$ a questão não é saber se permanecem fiéis às definições originais dadas por Freud ou Marx, ou, no caso do fetichismo, até mesmo pela história das religiões e da antropologia. Trata-se, aqui, de compreender se esses dois conceitos permitem um uso mais amplo e profundo que chegue ao coração da sociedade contemporânea - um uso que deveria decorrer de uma leitura inovadora dos conceitos de Marx e Freud, sem, contudo, tomá-la sempre ao pé da letra.

O fetichismo da mercadoria foi introduzido por Marx no primeiro capítulo de $O$ capital (1867), após ele ter analisado as categorias basilares da sociedade de produção de mercadorias, portanto, do capitalismo. O lado abstrato do trabalho, dito trabalho abstrato, ou seja, a simples distribuição de energia humana indiferenciada, medida pelo tempo, que forma 0 valor das mercadorias (material ou imaterial), o qual é representado pelo 
dinheiro. Marx descreve o fetichismo como uma relação social entre as coisas e uma relação de coisas entre as pessoas, expressão de um modo de produção no qual a produção dirige o homem ao invés de o homem dirigir a produção. Os homens colocam seu trabalho privado em relação não diretamente, mas em uma forma objetivada, sob uma aparência de coisas, isto é, como quantidade determinada de trabalho humano igual, expresso no valor de uma mercadoria. Todavia, não sabem que o fazem e atribuem os movimentos de seus produtos - as trocas entre os produtores e as proporções em que trocam a mercadoria - a uma qualidade desta última. $\mathrm{O}$ fetichismo é um processo inconsciente e coletivo que esconde a verdadeira natureza da produção capitalista. O próprio Marx o qualifica de "misterioso" e recorre à fórmula segundo a qual a mercadoria é "sensívelsupra-sensível" e é comparável à religião, em que o homem projeta suas forças sobre um ser transcendente do qual acredita depender.

Essas páginas de Marx - que ecoam até em algumas outras passagens de sua obra - foram negligenciadas pela maioria dos intérpretes de Marx ou compreendidas como a denúncia de uma mistificação que ocorre constantemente na sociedade capitalista: o fetichismo naturaliza - ou seja, apresenta falsamente como naturais as condições de exploração e de espoliação do mais-trabalho (logo, da mais-valia), que caracteriza o capitalismo, em prejuízo dos operários. Esse disfarce da realidade capitalista existe, evidentemente. Mas o fetichismo no sentido originário marxista vai muito além disso. Ele não é somente um fenômeno ideológico, pertencente à esfera da consciência, ou um embuste consciente da parte dos economistas burgueses que esconde a realidade cotidiana da exploração. A força do conceito de Marx está no fato de pôr a nu a inversão real que ocorre no capitalismo. O lado abstrato do trabalho (distribuição do trabalho como pura quantidade e sem consideração pelo seu conteúdo) prevalece sobre seu lado concreto; o valor mercantil prevalece sobre o valor de uso. Conta apenas a quantidade de trabalho desenvolvido e a parte de mais-trabalho que ele contém, porque se traduz em valor, em mais valor e, finalmente, em lucro. É secundário e irrelevante saber que coisa vem produzida por esse trabalho. Conta apenas seu aumento quantitativo, sua acumulação. Se são produzidas bombas ou grãos, isso importa muito pouco do ponto de vista do valor: produzem- 
se mais bombas e menos grãos se as bombas tiverem mais valor. 0 lado concreto da mercadoria - quer se trate de bens ou de serviços, não há diferença - torna-se subordinado, é um mero portador da única coisa que conta em uma economia capitalista: a quantidade de valor. 0 lado concreto, que é o que corresponde às necessidades e aos desejos humanos, e que deveria constituir o escopo da produção, na sociedade da mercadoria é reduzido a depender daquilo que, na verdade, dela deriva: sua representação abstrata.

Não se trata de uma ilusão ou de uma mise-en-scène, mas do âmbito mais profundo, e bem real, da lógica capitalista. Enquanto a exploração e a divisão de classes forem encontradas também em muitas outras sociedades, essa inversão entre o abstrato e o concreto é um traço distintivo do capitalismo. Não se trata, todavia, de um fenômeno "abstrato" ou secundário: ele explica o caráter destrutivo e cego da sociedade capitalista e constitui também a verdadeira raiz da devastação das bases naturais da vida por obra da economia².

Essa leitura do fetichismo ganhou muito terreno nos últimos decênios e substituiu amplamente o conceito mais problemático de "alienação" (do jovem Marx) e de "reificação" (de György Lukács). Mas que nexo pode ser estabelecido com o conceito de narcisismo?

Introduzido por Freud a partir de 1910, o narcisismo consiste essencialmente em uma indistinção entre si mesmo e o mundo circundante, e na tendência a perceber o mundo externo - os "objetos" em sentido amplo, inclusive as pessoas - somente como projeção e prolongamento do próprio eu. Trata-se de uma fase necessária no desenvolvimento psíquico da criança pequena, que se defende da penosa percepção de sua impotência real, criando uma sensação de fusão entre si mesma e o mundo que a leva a sentimentos de impotência. Problemático, ao contrário, é o "narcisismo secundário" do adulto que não superou verdadeiramente a fase narcisista, o que ocorre normalmente com o complexo de Édipo, em seguida ao qual a criança abandona sua fantasia de onipotência para

2 Para aprofundar essas explicações, não posso deixar de recomendar meu livro As aventuras da mercadoria: por uma crítica do valor, Roma, Aracne Editrice, 2019. 
substituí-la pelas satisfações limitadas, mas reais. No entanto, dado que esta renúncia é dolorosa, de traços mais ou menos fortes e normalmente inconsciente, o narcisismo originário pode continuar na vida adulta e assumir traços patológicos. O narcisista não está intimamente convencido da presença real de um mundo externo com o qual deve lidar, mas tenta colocar tudo e todos a seu serviço.

A importância do narcisismo como patologia é comumente limitada na obra de Freud, que se volta essencialmente para o estudo das neuroses. A partir dos anos 1970, sua importância aumentou bastante no discurso dos psicanalistas e psiquiatras, que doravante terão frequentemente muito o que fazer com pessoas que sofrem de distúrbios do tipo narcisista. Mas foi o estadunidense Christopher Lasch quem introduziu o narcisismo no discurso sociológico e político em seu livro A cultura do narcisismo (1979). Em sua opinião, a cultura contemporânea é profundamente marcada pelo narcisismo. Sobretudo a fantasia de fusão e de onipotência se encontra em fenômenos diversos, como o recurso à tecnologia e o New Age, o desinteresse pela política ou a arte minimalista. 0 narcisismo não se limita, pois, aos indivíduos particulares, mas impregna também as decisões coletivas.

Lasch, entretanto, tem pouco a dizer sobre as causas de uma tal mudança monumental. Por isso, impõe-se a necessidade de pensarmos juntos seu conceito de narcisismo, cuja fertilidade parece indubitável, e uma crítica do capitalismo contemporâneo centrada sobre os conceitos de valor, de trabalho abstrato e do fetichismo da mercadoria.

O aumento do "índice de narcisismo" no curso do século XX poderia estar ligado à difusão da lógica do valor e da mercadoria em todos os poros da sociedade. Essa lógica, com sua inversão do concreto e do abstrato, superou, há muito tempo, os confıns da produção de mercadorias para invadir e colonizar toda a esfera da vida, principalmente o consumo e as relações interpessoais. As mudanças na psique dos indivíduos são, ao mesmo tempo, causa e consequência da evolução no âmbito produtivo e seria muito redutor chamá-la apenas de "economia": a inversão entre o abstrato e o concreto é uma estrutura de base que permeia, de mil formas, toda a sociedade moderna e cuja origem se pode assinalar desde Descartes. Não é uma prioridade entre fatores "objetivos" e 
"subjetivos", entre "base" e "supraestrutura", entre "produção material" e "consciência". A neurose clássica, que predominava no tempo de Freud, era a consequência da renúncia imposta aos indivíduos que se obrigavam a dirigir a energia de sua própria libido para o trabalho produtivo. A partir dos anos 1970, o epicentro da vida social (aparentemente) se voltou para o consumo. A ordem dada aos indivíduos não era mais "trabalha, poupa, sacrifica-se, obedece" (como prolongamento do "reza e trabalha" da Igreja), mas "consome, divirta-se, gasta, endivida-se". Em vez de lembrarem aos sujeitos continuamente seus limites e sua dependência de instâncias superiores (Estado, religião, moral, hierarquia social), os incitam a superar todos os limites (pelo menos em imaginação) e a crer que o mundo está à disposição deles: o que é uma mentira, mas que permite levar a um consumo contínuo de mercadorias e imagens que, pelo menos, dão a impressão de que seja assim. Quanto mais os consumidores acreditarem que podem ter "tudo" na vida - e a publicidade os lembra disso pelo menos cem vezes por dia -, mais eles estarão dispostos a trabalhar como loucos e a endividar-se para comprar a sua droga (nos sentidos literal e figurado). E, portanto, a fazer a máquina girar cada vez mais sobrecarregada da reprodução capitalista.

Existe um nível mais profundo ainda do nexo entre narcisismo e fetichismo. O narcisismo consiste em uma desvalorização do mundo exterior ao sujeito: todos os objetos não são, no fundo, senão uma projeção do sujeito e não têm uma realidade própria, uma autonomia a ser respeitada. Esse sujeito, porém, de sua parte, é vazio, porque não é mais enriquecido pelas relações com outros objetos externos e permanece prisioneiro de seus fantasmas. Um indivíduo narcisista não é sequer forte, como se poderia crer, mas sim débil, porque "sem mundo". Ora, essa ausência de mundo, essa negação da qualidade diversificada do real em favor de uma única substância igual (o Eu), que por sua vez é privada de qualidade e abstrata, é aquilo que caracteriza o narcisismo - mas igualmente a lógica do valor e do trabalho abstrato. Pela lógica do valor, o mundo inteiro só conta pela quantidade privada de qualidade intrínseca, isto é, de mercadorias que se distinguem somente pela quantidade de valor e de trabalho abstrato que contêm. Trata-se de uma desvalorização do concreto - a multiplicidade do existente fica reduzida a consistir tão 
somente a partes de uma substância abstrata sempre igual (o valor). Para o narcisista, o mundo do não eu perde sua realidade autônoma, pela lógica fetichista da mercadoria, o mundo fora da acumulação de unidade de trabalho abstrato é somente uma sombra ${ }^{3}$. Eis porque fetichismo e narcisismo doravante vão juntos. Para a nossa maior desgraça.

\section{Referências}

JAPPE, Anselm. La société autophage: capitalisme, démesure et autodestruction. Paris: La Découverte, 2017.

JAPPE, Anselm. Le aventure delle merche: per una critica del valor. Roma: Aracne Editrice, 2019.

3 Aqui também, não posso deixar de recomendar, para um desenvolvimento detalhado, meu livro La société autophage: capitalisme, démesure et autodestruction, Paris, La Découverte, 2017. 